\title{
Thermal Comfort Analysis in Naturally-Ventilated Handball Arena Utilizing CFD Techniques
}

\author{
Ahmed A. Masoud', Essam E. Khalil ${ }^{2}$, Abdelmaged H. Ibrahim ${ }^{3}$ and Esmail M. ElBialy ${ }^{3}$ \\ ${ }^{1}$ Ph.D. Consultant, Giza 12613, Egypt. \\ ${ }^{2}$ Professor, Mechanical Power Engineering, Cairo University, Giza 12613, Egypt, AIAA fellow. \\ ${ }^{3}$ Assistant professor, Mechanical Power Engineering, Faculty of Engineering, Cairo University, Giza 12613, Egypt
}

\begin{abstract}
This work investigates the feasibility and thermal comfort of using natural ventilation in order to achieve thermal comfort in a handball arena with realistic dimensions and a full occupation of 4300 persons in the Gulf area. The work numerically simulates the temperature and velocity fields inside the full arena using computational fluid dynamics techniques at different internal loads, prevailing wind speeds, prevailing wind temperatures and prevailing wind angles. The work generates certain air opening configuration to be used for natural ventilation and the results show that natural ventilation is feasible if the following conditions are met simultaneously: the occupation density is $25 \%$ or less, sitting in the prevailing wind side, the lighting load does not exceed $50 \%$ of its full capacity, the prevailing wind temperature does not exceed $30{ }^{\circ} \mathrm{C}$ and the prevailing wind velocity is in range $3-4 \mathrm{~m} / \mathrm{s}$, where the upper limit arises from the requirement to avoid high velocities in the playing area. These conditions can be met during the training time and during parts of the day and over parts of the year hours making this method conditionally feasible.
\end{abstract}

\section{Introduction}

Natural ventilation is an effective measure to save energy consumed in buildings as well as to improve indoor air quality [1]. It depends on the pressure differences caused by wind and/or buoyancy forces that force the indoor air to be replaced by outdoor air. The design of naturally ventilated buildings takes into consideration the regional and site-specific wind patterns on a daily and annual basis to maximize occupant comfort at minimum energy cost. The building envelope, the external climate temperature, radiation, humidity and wind speed and direction determine the heating and cooling requirements of the building.

Natural ventilation design is very complicated and must be analyzed in details for optimum results. However, it is very difficult to achieve this goal, due to the variability of the outside environmental parameters and also the variability of the internal thermal load $[2,3]$. The conditions for natural ventilation cannot be controlled as in mechanical ventilation. Therefore, careful attention must be paid to natural forces, particularly those of wind and temperature while it is difficult to control and measure these unpredictable forces. A tool is needed that enables the designers to easily manipulate the building's design in order to observe trends and evaluate various potential designs. This tool is for these reasons; the potential for computational fluid dynamics (CFD) in the field of natural ventilation is very significant and needs to be addressed. In this work, Ansys-Fluent software is used to numerically- simulate a published experimental work in order to validate the numerical model' to simulate air flow patterns inside the arena $[4,5,6,7$ and 8]. These considered open and closed arenas for multipurpose games. In particular, sports halls have special considerations for air velocities inside the playing area and thus they require more control as well as more flexibility in. The indoor air velocity in the spectators' zone doesn't have any limitations except the drafts that may cause discomfort. Fluctuating wind speeds and severe outdoor temperatures may stand as a barrier from using natural ventilation, however there is a mixed mode ventilation systems that can accommodate between the mechanical and natural ventilation options according to the outside conditions.

\section{Case Study Description}

This section describes the handball arena considered in this work. The arena has a capacity of 4300 person in a full event attendance. It measures $95 \mathrm{~m}$ length, $75 \mathrm{~m}$ width and $22 \mathrm{~m}$ height, with a type concrete-enforced roof. The location is chosen to be in an area with a hot severe air condition, typical of gulf's weather conditions. 
The area is selected with high prevailing wind speeds, while the outdoor conditions vary all over the year.

The natural ventilation technique can be activated at certain times where acceptable outdoor conditions yield acceptable thermal comfort level and use active air conditioning otherwise. The arena model is shown in Fig. 1 where the air openings are arranged along the arena perimeter with equal sizes $(1 \mathrm{~m} \times 0.5 \mathrm{~m})$ while the distance between the openings gets closer near the arena corners in order to force the air to follow a cross ventilation pattern. For numerical simulation purposes, the arena is placed inside a chamber whose dimensions were selected based on the results of Allocca [3] in order to validate the present procedure and are presented in Fig.2.

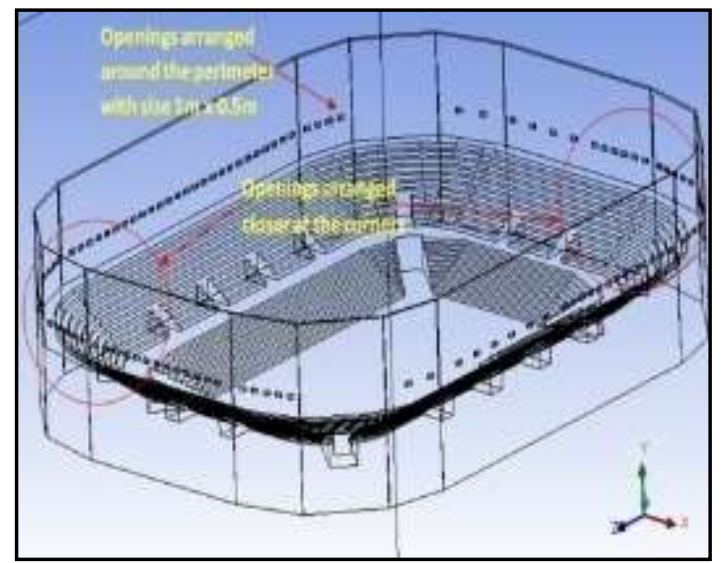

Fig. 1. The arena configuration with the air openings around the arena

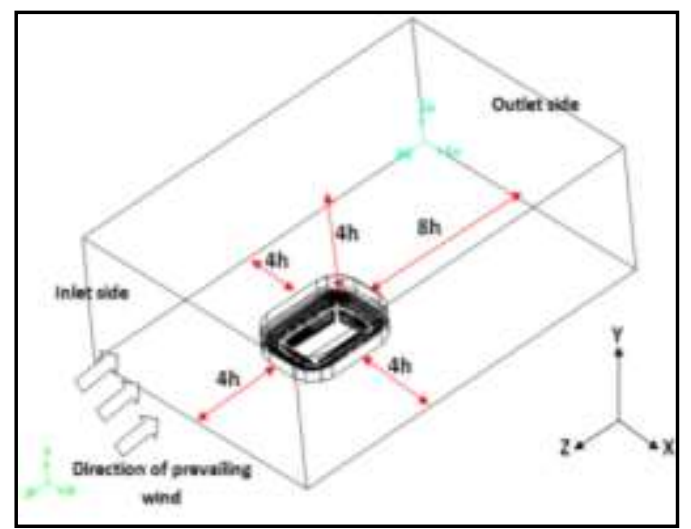

Fig. 2. The dimensions of the chamber used for numerical simulation

In order to evaluate the thermal comfort, the temperature and the amplitude of the 3D air-velocity vector are numerically simulated at ten different points carefully selected at different locations in the seating and playing area as depicted in Fig.3.

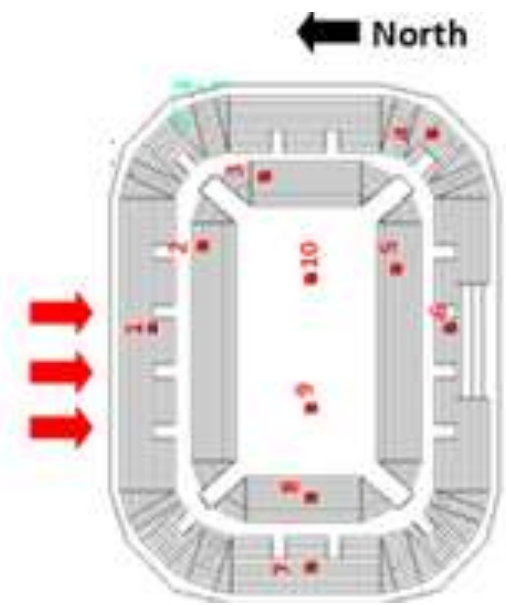

Fig. 3. the location of ten selected points where the temperatures and velocity values are used to evaluate the thermal comfort level

\section{Grid Generation and Validation}

The grid generation was carried-out via Ansys-Fluent [7] which generated uniform three-dimensional fine tetrahedral finite volume mesh for the whole arena and numerical-simulation chamber. Because the air openings are not regularly distributed, no symmetries exist and the numerical solution was carried-out for the complete domain. Then, the initial boundary conditions were specified and the governing equations were solved. The meshing pattern was made dense around and inside the arena by applying a size function that starts from 0.06 element size with a growth rate of 1.25 and a maximum element size of 1(Fig.4). The mesh independence test was carried out by solving the continuity and momentum equations inside the arena domain in three-dimensional form and steady-state conditions using constant material properties under the pressure-velocity coupling scheme and using the realizable $\mathrm{k}-\varepsilon$ turbulence model. The mesh was refined until the difference between the results did not exceed $0.5 \%$. This yielded the use of a total number of 5 million mesh elements.

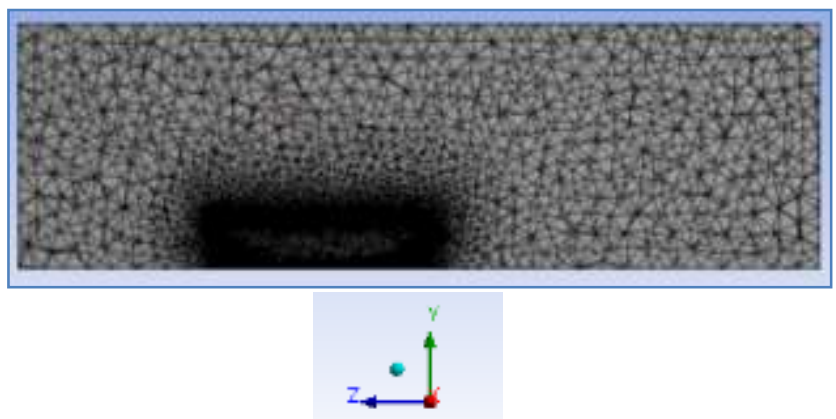

Fig.4.The numerical mesh used in this work for the arena and the numerical-simulation chamber 
In order to validate the simulated $2 \mathrm{D}$ velocity components (in the $\mathrm{Y}$ and $\mathrm{Z}$ directions), the simulated values were compared to those measured by Alloca [] in a single-sided naturally-ventilated room along ten selected vertical lines shown in Fig.5.

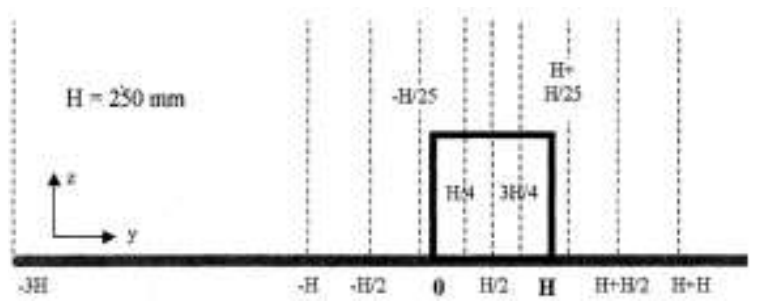

Fig. 5. The line locations of the velocity measurements made by Alloca [3] and used to validate the numerical simulation made in this work

Then, the results obtained using three different numerical models (Large Eddy Simulation (LES), Realizable K- $\varepsilon$ model and Re-Normalization Group k- $\varepsilon$ model) and Alloca's experimental values were compared in Fig. 6, yielding that the Realizable K- $\varepsilon$ model produced the best agreement amongst the three models and was used in this model.
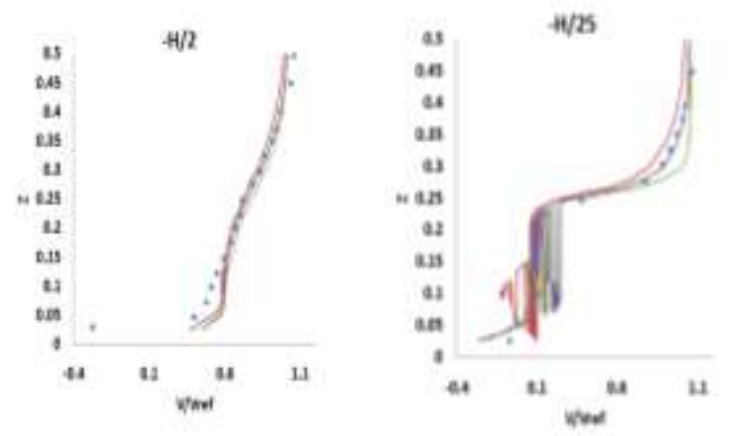

Fig.6a. Comparison between experimental results Allocea [3] and current CFD simulations for the velocity component in the $y$-direction
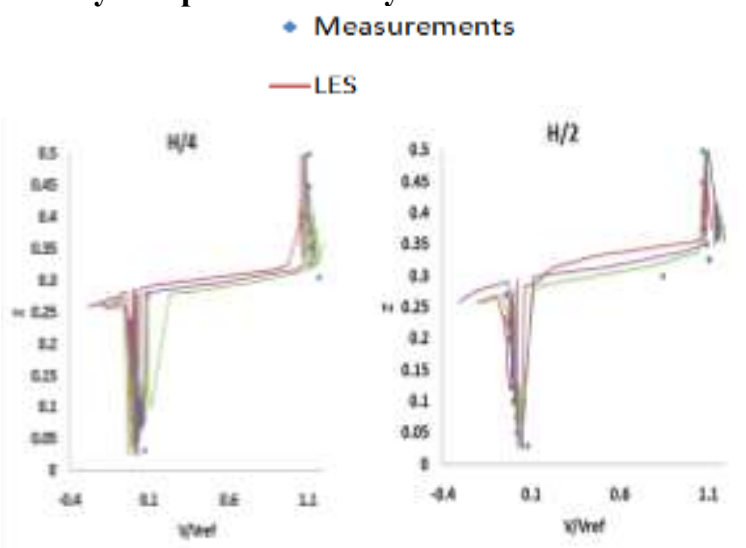

Fig.6b. Comparison between experimental results Allocea [3] and current CFD simulations for the velocity component in the y-direction

\section{Results and Discussion}

\subsection{Basic Case}

This section presents the results of a basic case numerically simulated under the following conditions: a prevailing wind speed of $3 \mathrm{~m} / \mathrm{s}$ (from $90^{\circ}$ angle with respect to north), a prevailing wind temperature of $27^{\circ} \mathrm{C}$, an internal thermal load of $20 \mathrm{~W} / \mathrm{m}^{2}$ for seating area and $25 \mathrm{~W} / \mathrm{m}^{2}$ for lighting. The numerical-simulated velocity contours and temperature contours are then presented in Fig. 7at three different heights $(\mathrm{Y}=1.5,4$ and $8 \mathrm{~m})$ corresponding to the level of the playing area (points 9 and 10), the low-level in the seating area (points 2, 3, 5 and 8) and the high-level in the seating area (1, 4,6 and 7), respectively. The results are presented for the temperature and velocity contours in Fig.7. The achievement of thermal comfort is estimated via ref of Berkeley California http://comfort.cbe.berkeley.edu/s which employs the adaptive method to check compliance with ASHRAE Standard 55-2017based on the simulated indoor temperature, indoor air speed and the outdoor temperature.

Table 1 indicates the simulated temperature and air velocity magnitude at the ten selected points, as well as their exact locations inside the arena. The points that achieve adaptive thermal comfort according to the described criterion are underlined in the table. In this work, the percentage of the number of points that satisfied thermal comfort to the total number of points is denoted as the $\mathrm{N} \%$.

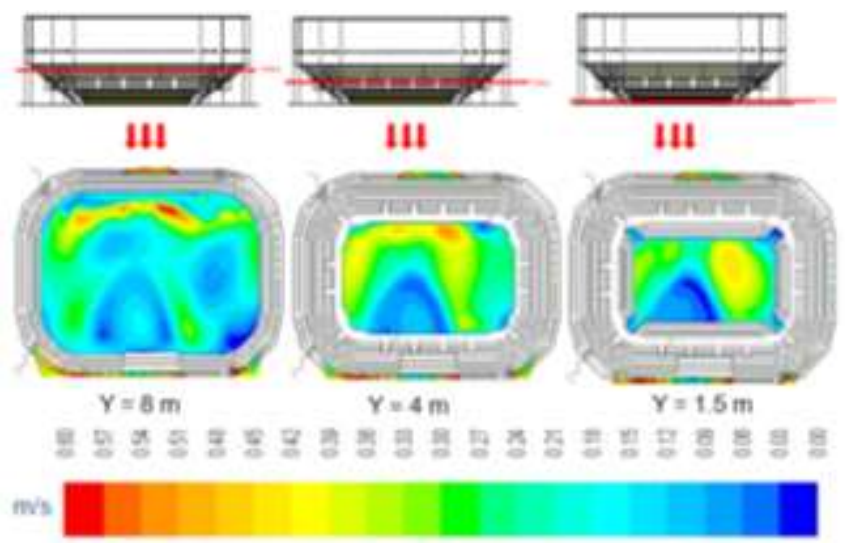

Fig.7a. The Velocity contours at three sections $Y=1.5$, 4 and $8 \mathrm{~m}$, the conditions of this case are: Prevailing wind speed of $3 \mathrm{~m} / \mathrm{s}$ (from $90^{\circ}$ angle with respect to north), a prevailing wind temperature of $27^{\circ} \mathrm{C}$, an internal thermal load of $20 \mathrm{~W} / \mathrm{m}^{2}$ for seating area and $25 \mathrm{~W} / \mathrm{m}^{2}$ for lighting 


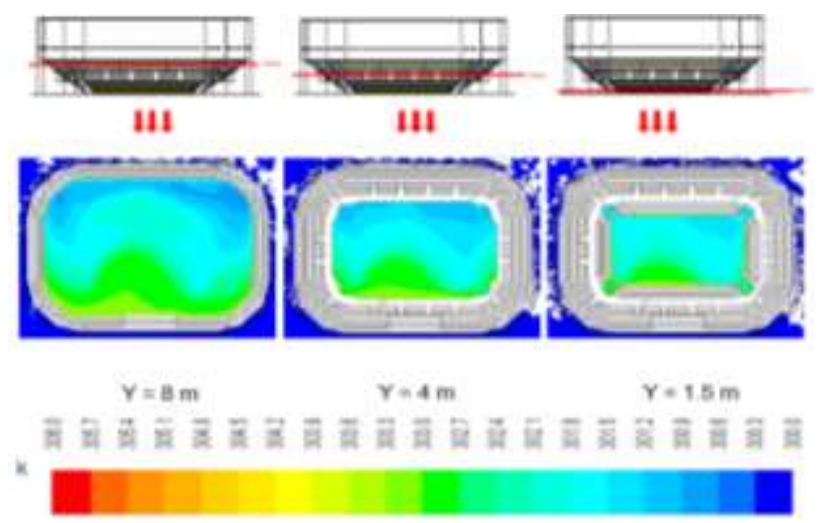

Fig.7b. The temperature contours (right column) at three sections $Y=1.5,4$ and $8 \mathrm{~m}$, the conditions of this case are: Prevailing wind speed of $3 \mathrm{~m} / \mathrm{s}$ (from $90^{\circ}$ angle with respect to north), a prevailing wind temperature of $27^{\circ} \mathrm{C}$, an internal thermal load of 20 $\mathrm{W} / \mathrm{m}^{2}$ for seating area and $25 \mathrm{~W} / \mathrm{m}^{2}$ for lighting

In this case (hereinafter referred to as case 00), the velocity contours shown in Fig. 7 reveal that the side of the arena facing the prevailing wind direction experienced high air velocities in the range $0.03-0.6 \mathrm{~m} / \mathrm{s}$. Some of these high-velocity points are shown in Table 1 (points 1, 2, 3, 5, 7, 8 and 10). The temperature contours presented in Fig. 7 show a gradual increase in the temperature from the high-velocity side facing the prevailing wind direction to the low-velocity side in th temperature range $(301-304 \mathrm{~K})$. In this case, the highlevel seating area, which experiences low-temperature levels, is to be avoided because the incoming high-speed air passed from the straight openings located directly above this area and only those sitting further downstream would be able to experience the high air speed.

Table 1. The temperatures and velocity magnitudes at the ten selected points

\begin{tabular}{|c|c|c|c|c|c|c|c|c|c|}
\hline \multicolumn{6}{|c|}{ the ten selected points } & \multirow{2}{*}{$\begin{array}{l}\text { Case } \\
\text { No. }\end{array}$} & \multirow{2}{*}{$\begin{array}{c}\text { Arena's } \\
\text { orientation }\end{array}$} & \multirow{2}{*}{$\begin{array}{c}\text { wind } \\
\text { velocity } \\
\mathrm{m} / \mathrm{s} \\
\end{array}$} & \multirow{2}{*}{$\begin{array}{c}\text { wind } \\
\text { temperature } \\
{ }^{\circ} \mathrm{C}\end{array}$} \\
\hline Point \# & $\begin{array}{l}\text { Point's X- } \\
\text { location }\end{array}$ & $\begin{array}{l}\text { Point's Y- } \\
\text { location }\end{array}$ & $\begin{array}{l}\text { Point's Z- } \\
\text { location }\end{array}$ & $\mathbf{T}\left({ }^{\circ} \mathrm{C}\right)$ & $\mathbf{V}(\mathbf{m} / \mathbf{s})$ & & & & \\
\hline & & & & & & \multirow[b]{2}{*}{01} & \multirow[b]{2}{*}{ Zero angle } & \multirow[b]{2}{*}{3} & \multirow[b]{2}{*}{27} \\
\hline point-1 & 125 & 8 & 263 & 27.9 & 0.13 & & & & \\
\hline point-2 & 107 & 6 & 256 & 27.9 & 0.13 & 02 & $45^{\circ}$ angle & 3 & 27 \\
\hline \multirow{2}{*}{ point-3 } & \multirow[t]{2}{*}{95} & \multirow[t]{2}{*}{6} & \multirow[t]{2}{*}{244} & \multirow{2}{*}{$\underline{28.1}$} & \multirow{2}{*}{$\underline{0.28}$} & 03 & $90^{\circ}$ angle & 2 & 27 \\
\hline & & & & & & 04 & $90^{\circ}$ angle & 4 & 27 \\
\hline point-4 & 92 & 9 & 212 & 29.8 & 0.03 & 05 & $90^{\circ}$ angle & 3 & 30 \\
\hline point-5 & 118 & 4 & 218 & $\underline{29.6}$ & $\underline{0.30}$ & \multirow{2}{*}{06} & \multirow{2}{*}{$90^{\circ}$ angle } & \multirow{2}{*}{3} & \multirow{2}{*}{33} \\
\hline point -6 & 124 & 7 & 208 & 30.0 & 0.07 & & & & \\
\hline point-7 & 168 & 8 & 231 & 29.1 & 0.20 & 07 & $90^{\circ}$ angle & 3 & 27 \\
\hline
\end{tabular}

\begin{tabular}{|l|c|c|c|l|l|}
\hline point-7 & 168 & 8 & 231 & 29.1 & 0.20 \\
\hline point-8 & 159 & 5 & 231 & $\underline{\mathbf{2 9 . 1}}$ & $\underline{\mathbf{0 . 3 5}}$ \\
\hline point-9 & 140 & 1.5 & 233 & 29.3 & 0.07 \\
\hline point-10 & 120 & 1.5 & 233 & $\underline{\mathbf{2 8 . 8}}$ & $\underline{\mathbf{0 . 3 7}}$ \\
\hline
\end{tabular}

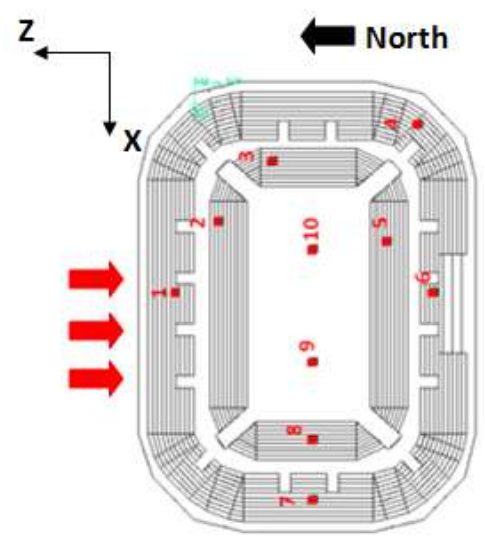

Fig.8: Arena Orientation (short Side)

With respect to case-01 (zero angle orientation), the number of points satisfying thermal comfort increased by $50 \%$ and with respect to case- 02 ( $45^{\circ}$ angle orientation) the number of points satisfying thermal comfort increased by $100 \%$.(see Fig. 8 )

The following section investigates the following: The natural ventilation method is investigated under three arena's orientations $\left(0^{\circ}, 45^{\circ}\right.$ and $\left.90^{\circ}\right)$ with respect to the north direction, three prevailing wind speeds $(2 \mathrm{~m} / \mathrm{s}, 3$ $\mathrm{m} / \mathrm{s}, 4 \mathrm{~m} / \mathrm{s})$, three prevailing wind temperatures $(27 \mathrm{C}, 30$ $\mathrm{C}$ and $33 \mathrm{C}$ ) and two indoor thermal loads $25 \mathrm{~W} / \mathrm{m}^{2}$ (represent occupation density 25\%) and $50 \mathrm{~W} / \mathrm{m}^{2}$ (represent occupation density 60\%) where the investigation considered the event at $8 \mathrm{pm}$ where no direct solar radiation gained and only internal loads shall be considered in simulations.

Table 2. The conditions of all the cases investigated with the natural ventilation method

Seats: $20 \mathrm{w} / \mathrm{m}^{2}$ and roof: $25 \mathrm{w} / \mathrm{m}^{2}$ 


\subsection{Effects of arena orientation}

Case-01: Zero angle arenas' orientation (aligned east)

The results of zero angle orientation are presented for the temperature and velocity contours in Fig.9. and Table.3 indicates the velocities and temperatures at the selected points. Same conditions as in Figure 7 except that the arena is made parallel to the prevailing wind direction
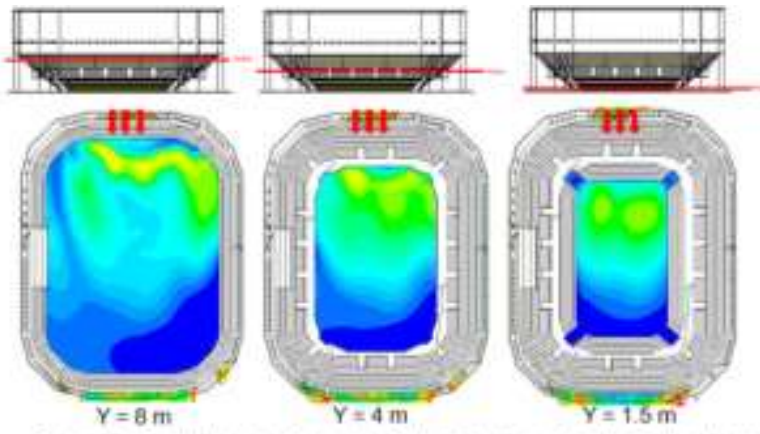

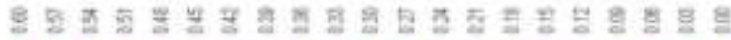
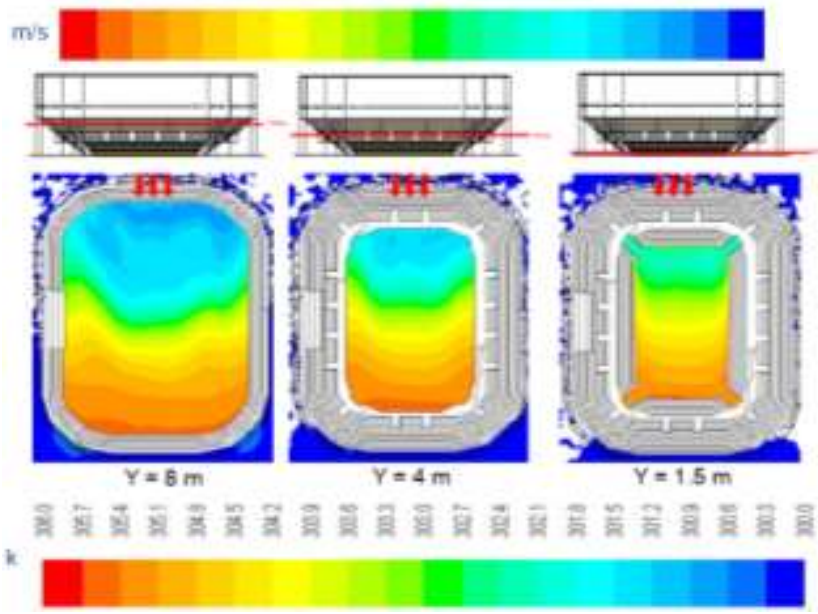

Fig.9. The velocity contours and temperature contours at three sections $Y=1.5,4$ and $8 \mathrm{~m}$.

Table 3.Predicted temperatures and velocities at the 10 selected points

\begin{tabular}{|r|r|r|}
\hline & $\mathbf{T}\left({ }^{\circ} \mathbf{C}\right)$ & $\mathbf{V}(\mathbf{m} / \mathbf{s})$ \\
\hline point-1 & 31.1 & 0.06 \\
\hline point-2 & 32.0 & 0.01 \\
\hline point-3 & 32.3 & 0.01 \\
\hline point-4 & 32.3 & 0.07 \\
\hline point-5 & 32.0 & 0.05 \\
\hline point-6 & 31.0 & 0.13 \\
\hline point-7 & 27.9 & 0.14 \\
\hline point-8 & 28.2 & 0.29 \\
\hline point-9 & 30.1 & 0.29 \\
\hline point-10 & 32.0 & 0.03 \\
\hline
\end{tabular}

In this case (hereinafter referred to as case-01), the velocity contours shown in Fig. 9 reveal that the side of the arena facing the prevailing wind direction experienced high air velocities in the range 0.03-0.33 $\mathrm{m} / \mathrm{s}$. Some of these high-velocity points are shown in Table 3 ( 8 and 9). The temperature contours presented in Fig. 9 show a gradual increase in the temperature from the high-velocity side facing the prevailing wind direction to the low-velocity side in th temperature range $(300 \mathrm{~K}-304 \mathrm{~K})$.

In this case, the high-level seating area, which experiences low-temperature levels, is to be avoided because the incoming high-speed air passed from the straight openings located directly above this area and only those sitting further downstream would be able to experience the high air speed.

\section{Case-02: $45^{\circ}$ angle arena's orientation}

The results of $45^{\circ}$ angle orientation is presented for the temperature and velocity contours in Fig 10 . and Table. 4 indicates the velocities and temperatures.
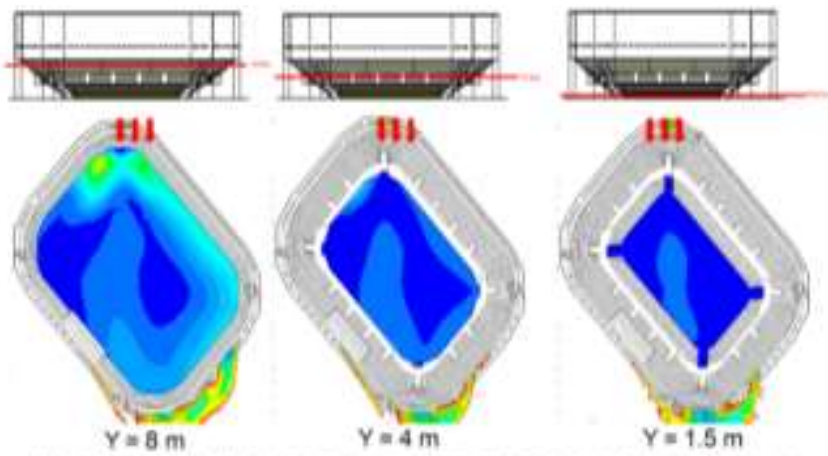

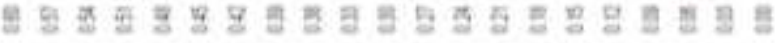
mvs

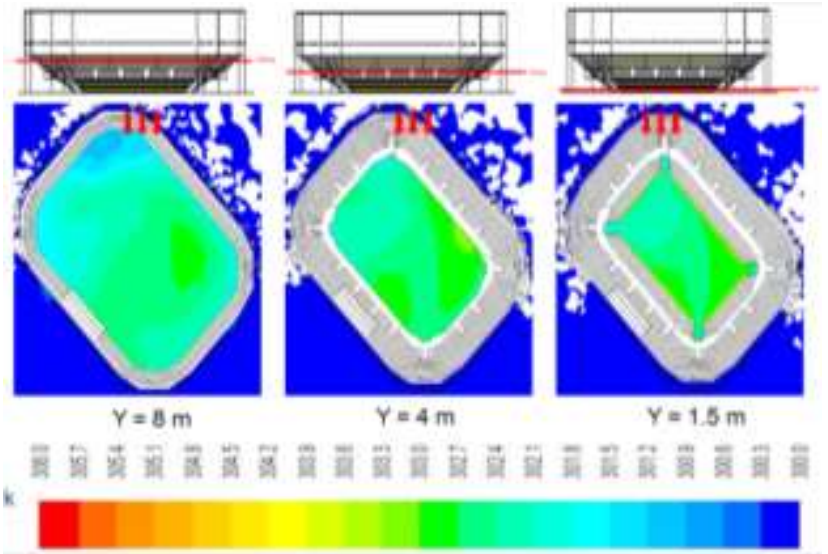

Fig.10. The velocity contours (upper column) and temperature contours (lower column) at three sections $Y=1.5,4$ and $8 \mathrm{~m}$. Same conditions as in Figure 7 except that the arena is rotated $45^{\circ}$ (anti-click wise) from the prevailing wind direction 
In this case (hereinafter referred to as case-02), the velocity presented in Fig. 11 reveal poor indoor air velocities that in the range $0.01-0.027 \mathrm{~m} / \mathrm{s}$. Table 4 show that there is no point achieved the required indoor air velocity. The temperature contours presented in Fig. 9 show a uniform distribution all over the arena and as remarked from the temperatures at points in Table.4 which has average of $303.5 \mathrm{~K}$. This orientation has an acceptable uniform temperature distribution but the indoor air velocity is very low and did not match the thermal comfort criterion [9].

\subsection{Effects of air velocity}

Case-03: $90^{\circ}$ angle orientation at prevailing wind speed $2 \mathrm{~m} / \mathrm{s}$

The results of $90^{\circ}$ angle orientation with a prevailing wind speed $2 \mathrm{~m} / \mathrm{sis}$ presented for the temperature and velocity contours in Fig.12. Table.5 indicates the velocities and temperatures at the selected points.
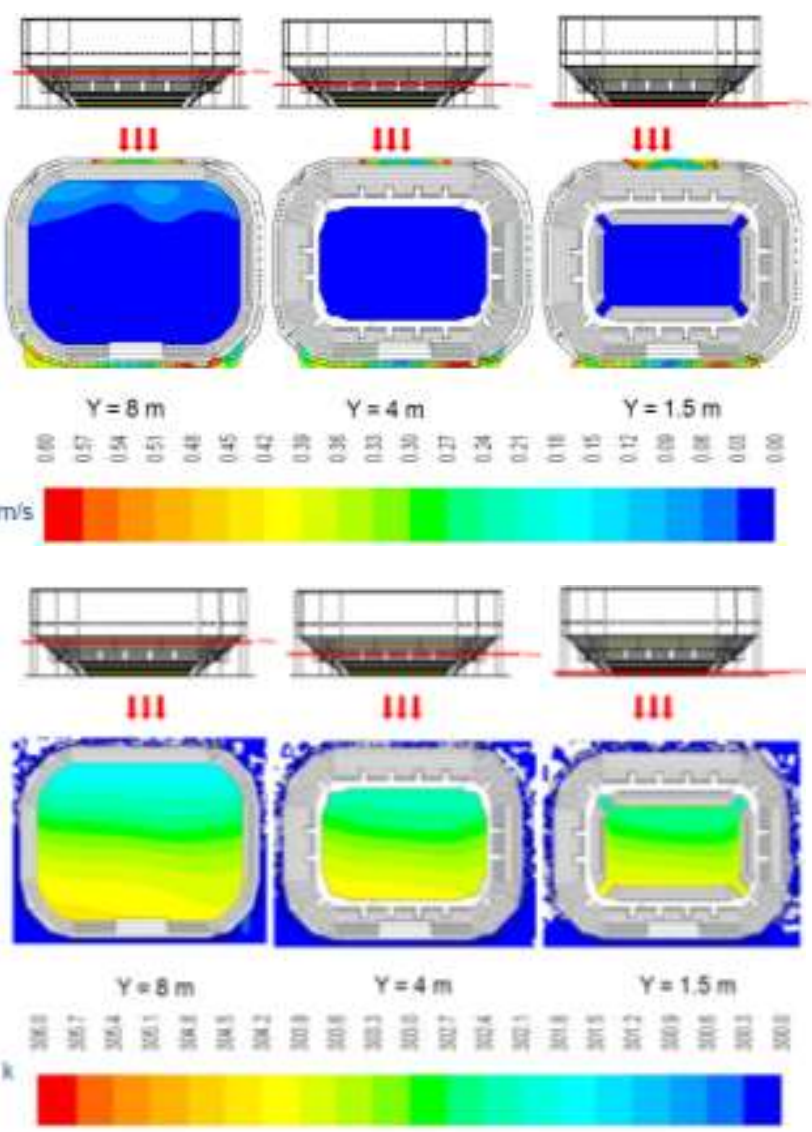

Fig.11. The velocity and temperature contours at three sections $Y=1.5,4$ and $8 \mathrm{~m}$. The prevailing wind speed is reduced to $2 \mathrm{~m} / \mathrm{s}$

Table 4. The resulting temperatures and velocities at the 10 selected points

\begin{tabular}{|r|r|r|}
\hline & $\mathbf{T}\left({ }^{\circ} \mathbf{C}\right)$ & $\mathbf{V}(\mathbf{m} / \mathbf{s})$ \\
\hline point-1 & 29.3 & 0.17 \\
\hline point-2 & 29.8 & 0.06 \\
\hline point-3 & 29.4 & 0.08 \\
\hline point-4 & 29.3 & 0.08 \\
\hline point-5 & 29.6 & 0.06 \\
\hline point-6 & 29.5 & 0.05 \\
\hline point-7 & 28.9 & 0.05 \\
\hline point-8 & 29.4 & 0.01 \\
\hline point-9 & 29.3 & 0.03 \\
\hline point-10 & 29.7 & 0.01 \\
\hline
\end{tabular}

Table 5. The resulted temperatures and velocities at the 10 selected points

\begin{tabular}{|r|r|r|}
\hline & $\mathbf{T}\left({ }^{\circ} \mathbf{C}\right)$ & $\mathbf{V}(\mathbf{m} / \mathbf{s})$ \\
\hline point-1 & 28.6 & 0.05 \\
\hline point-2 & 28.9 & 0.03 \\
\hline point-3 & 29.6 & 0.05 \\
\hline point-4 & 30.9 & 0.02 \\
\hline point-5 & 30.9 & 0.05 \\
\hline point-6 & 31.1 & 0.02 \\
\hline point-7 & 30.5 & 0.04 \\
\hline point-8 & 30.5 & 0.035 \\
\hline point-9 & 30.2 & 0.022 \\
\hline point-10 & 30.1 & 0.015 \\
\hline
\end{tabular}

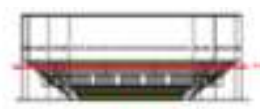

111
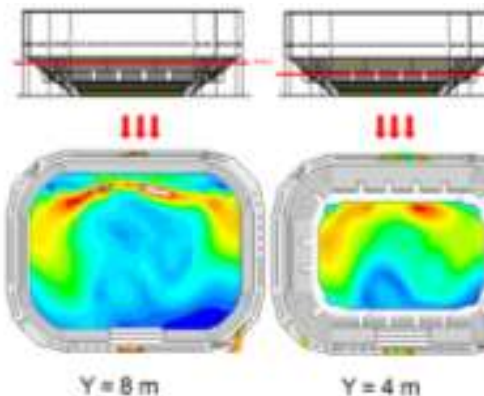

III

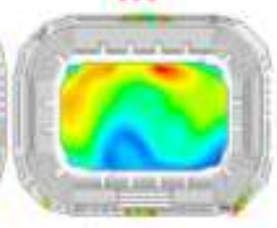
mis

Fig. 12. The velocity contours at three sections $Y=1.5$, 4 and $8 \mathrm{~m}$. Same conditions as in Figure 7 except that the prevailing wind speed is increased to $4 \mathrm{~m} / \mathrm{s}$ 
Table 6. The resulted temperatures and velocities at the 10 selected points

\begin{tabular}{|r|r|r|}
\hline & $\mathbf{T}\left({ }^{\circ} \mathbf{C}\right)$ & $\mathbf{V}(\mathbf{m} / \mathbf{s})$ \\
\hline point-1 & 27.7 & 0.15 \\
\hline point-2 & 27.7 & 0.29 \\
\hline point-3 & 27.9 & 0.43 \\
\hline point-4 & 29.0 & 0.03 \\
\hline point-5 & 29.1 & 0.19 \\
\hline point-6 & 29.3 & 0.05 \\
\hline point-7 & 28.8 & 0.34 \\
\hline point-8 & 28.9 & 0.42 \\
\hline point-9 & 28.6 & 0.20 \\
\hline point-10 & 28.4 & 0.43 \\
\hline
\end{tabular}

In this case (hereinafter referred to as case-04), the velocity contours shown in Fig. 12 reveal that the side of the arena facing the prevailing wind direction experienced high air velocities in the range $0.3-0.6 \mathrm{~m} / \mathrm{s}$. Some of these high-velocity points are shown in Table 6 $(2,3,5,7,8,9$ and 10). The temperature contours presented in Fig. 12 show a gradual increase in the temperature from the high-velocity side facing the prevailing wind direction to the low-velocity side in the temperature range $(300 \mathrm{~K}-302.7 \mathrm{~K})$.

the points that satisfied the thermal comfort criterion [ref.] can be used to indicate the recommended seating areas, which indicate in this case that the spectators are recommended to sit in the areas where the point $(2,3,7$ and 8) are located, which are in the low and high level seating areas. So the indoor air velocities and temperatures are highly affected and the thermal criterion achieved in more locations, but it shall not increase than $4 \mathrm{~m} / \mathrm{s}$ in order to keep the velocities in the playing area within the acceptable limits.

\subsection{Effects of prevailing wind temperature}

Case-05: $90^{\circ}$ angle orientation at prevailing wind temperature $30{ }^{\circ} \mathrm{C}$

The results of $90^{\circ}$ angle orientation with a prevailing wind temperature $30{ }^{\circ} \mathrm{Cis}$ presented for the temperature and velocity contours in Fig.13. Table.7 indicates the velocities and temperatures at the selected points.

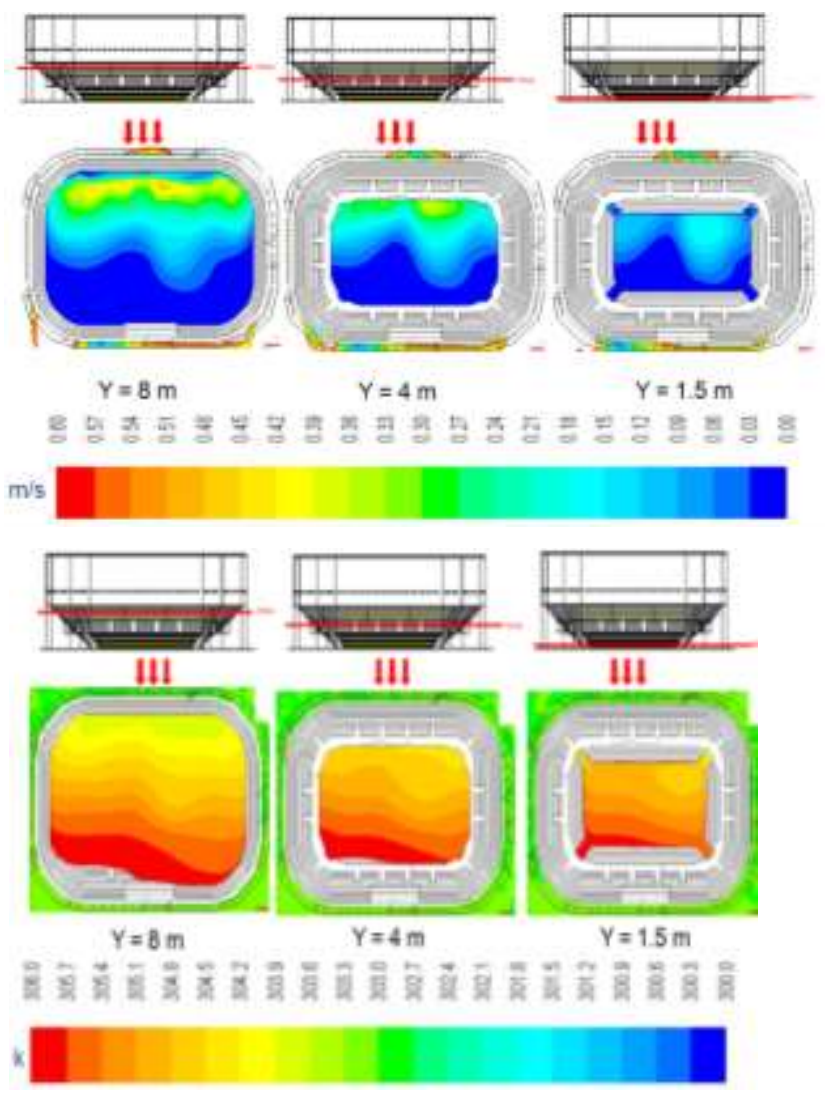

Fig.13. The velocity contours (left column) and temperature contours (right column) at three sections $Y=1.5,4$ and $8 \mathrm{~m}$. Same conditions as in Figure 7 except that the prevailing wind temperature increased to $30{ }^{\circ} \mathrm{C}$

Table 7.The resulted temperatures and velocities at the 10 selected points

\begin{tabular}{|c|c|c|}
\hline & $\mathbf{T ~}\left({ }^{\circ} \mathbf{C}\right)$ & $\mathbf{V}(\mathbf{m} / \mathbf{s})$ \\
\hline point-1 & 30.7 & 0.29 \\
\hline point-2 & 31.1 & 0.31 \\
\hline point-3 & 31.5 & 0.18 \\
\hline point-4 & 32.6 & 0.02 \\
\hline point-5 & 32.7 & 0.02 \\
\hline point-6 & 32.9 & 0.01 \\
\hline point-7 & 32.4 & 0.03 \\
\hline point-8 & 32.5 & 0.05 \\
\hline point-9 & 32.3 & 0.01 \\
\hline point-10 & 32.1 & 0.12 \\
\hline
\end{tabular}

In case- 05 , increasing the temperature of the prevailing wind to $30{ }^{\circ} \mathrm{C}$ affected the indoor air velocities as shown in Fig. 13, since the increase of air temperature arise the 
change of the air density which affected the air velocities as a wind driven ventilation. The velocity range is 0.01 $0.36 \mathrm{~m} / \mathrm{s}$ and only two points (1 and 2$)$ that match with the required to achieve thermal comfort.

The temperature contours show that the gradual temperature increase from high pressure side down to the low pressure side, the temperatures inside the arena exceed $31.7^{\circ} \mathrm{C}$ at most of locations in the occupied zone. This arise the effect of using natural ventilation with prevailing wind temperature $30{ }^{\circ} \mathrm{C}$, where only one side of the arena (at points 1 and 2) with limited number of occupants will be satisfied.

Increasing the temperature of the prevailing wind to 33 ${ }^{\circ} \mathrm{C}$ affected the indoor air velocities, since the increase of air temperature arise the change of the air density which affected the air velocities as a wind driven ventilation. The velocity range is $0.01-0.33 \mathrm{~m} / \mathrm{s}$ and only two points (1 and 2) that match with the required to achieve thermal comfort as depicted in Table 8. The temperature contours show that the temperatures inside the arena exceed 31.7 ${ }^{\circ} \mathrm{C}$ at all locations in the occupied zone. In coupling with the velocities inside the arena, the thermal comfort conditions did not achieved from the temperature side at any point.

\section{Conclusions}

Natural ventilation is one of the most cost effective methods to decrease the power consumption of HVAC systems used with this kind of buildings. Applying natural ventilation has a certain limitations that shall be considered in the design phase. This sport stadium with the current openings configuration is capable of using natural ventilation with maximum occupation percentage of $25 \%$ as the results show that the thermal comfort criterion is not maintained with $50 \%$ occupation. On the other hand, the design phase should consider that the best arena's orientation is that normal on the direction of the prevailing wind direction. Availability of proper outdoor conditions is one of the important factors to use natural ventilation, prevailing wind speeds and temperatures are dependent on the location of the arena. In our case to make this method conditionally feasible, the prevailing wind speeds shall not be higher than $4 \mathrm{~m} / \mathrm{s}$ and the limitations on the indoor speeds stems from the constrains on the air speeds in the playing area and the prevailing wind temperature shall not be higher than 30 ${ }^{\circ} \mathrm{C}$.

\section{References}

1. E.E.Khalil, "Life cycle cost analyses of airconditioning systems in commercial buildings in Egypt," 2nd ICGSI conference, ChiangRai, Thailand, 2009.
2. Q., Chen, "Comparison of different k-e models for indoor airflow computations," Numerical Heat Transfer, Vol. 28, 1995, pp.353-369.

3. C., Allocca, Q.,Chen, and I.R.Glicksman,"Design analysis of single-sided natural ventilation," Energy and buildings, Vol. 35, 2003, pp.785-795.

4. ASHRAE Standard (62-2016), Ventilation for acceptable indoor air quality. Atlanta, 2016.

5. Natural ventilation. [Online] http://www.enviroware. com/windrose.cgi/.

6. F.Simmons, A.J.Martin, "Making natural ventilation work”, BSRIA Limited, 2000.

7. S.Lestinen, H. Nyyssölä,"The Measurements in Malmö Arena Indoor Environment," Report, ArenaIC project, OlofGranlund Oy, Finland, 2010.

8. Wu.Xuehui, Li.Xiaodong, "Numerical Simulation of displacement ventilation in a gymnasium in a large space building," HVAC Technologies for Energy Efficiency, Vol. IV-5-2, 2006.

9. E.E.Khalil, , Air Distribution in Buildings, Taylor and Francis, CRC Press, 2013. 